\title{
Relationship Between Mental Health Literacy And Help Seeking Behavior Among Undergraduate Students
}

\author{
Nuramalina Samar, Asma Perveen
}

To Link this Article: http://dx.doi.org/10.6007/IJARBSS/v11-i6/10113

DOI:10.6007/IJARBSS/v11-i6/10113

Received: 04 April 2021, Revised: 27 April 2021, Accepted: 19 May 2021

Published Online: 09 June 2021

In-Text Citation: (Samar \& Perveen, 2021)

To Cite this Article: Samar, N., \& Perveen, A. (2021). Relationship Between Mental Health Literacy And Help Seeking Behavior Among Undergraduate Students. International Journal of Academic Research in Business and Social Sciences, 11(6), 216-230.

\section{Copyright: @ 2021 The Author(s)}

Published by Human Resource Management Academic Research Society (www.hrmars.com)

This article is published under the Creative Commons Attribution (CC BY 4.0) license. Anyone may reproduce, distribute, translate and create derivative works of this article (for both commercial and non-commercial purposes), subject to full attribution to the original publication and authors. The full terms of this license may be seen at: http://creativecommons.org/licences/by/4.0/legalcode

Vol. 11, No. 6, 2021, Pg. 216 - 230

Full Terms \& Conditions of access and use can be found at http://hrmars.com/index.php/pages/detail/publication-ethics 


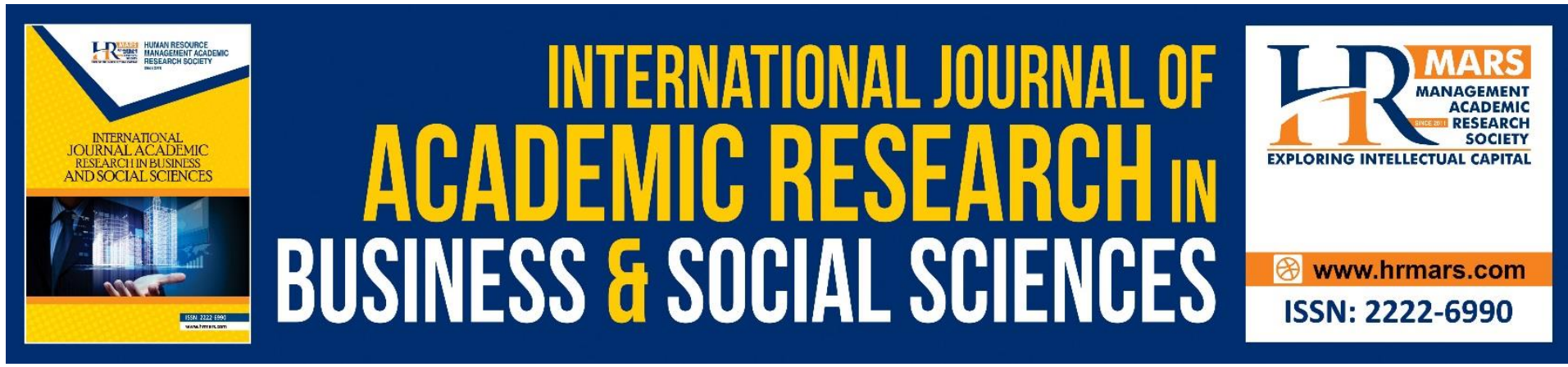

\title{
Relationship Between Mental Health Literacy And Help Seeking Behavior Among Undergraduate Students
}

\author{
Nuramalina Samar \\ Department of Psychology and Counseling, Faculty of Human Development Sultan Idris \\ Education University, Malaysia \\ Asma Perveen \\ Department of Psychology and Counseling, Faculty of Human Development Sultan Idris \\ Education University Malaysia
}

\begin{abstract}
The aim of the study is to identify the level of mental health literacy among undergraduate students to explore the relationship between mental health literacy and help seeking behavior among UPSI students and to identify the significant difference in mental health literacy score for students who have encountered people with mental health disorders. The study adapted cross-sectional quantitative survey design. Mental Health Literacy Scale (MHLS) and General Help-Seeking Questionnaire are used in this study. N=130 UPSI students ( $n=25$ male, $n=105$ female) completed the online survey which measure multiple dimensions of mental health literacy and help seeking behavior. The level of mental health literacy of undergraduate students was measured through the mean score of the MHLS. Result revealed a mean score of the MHLS obtained from the sample is $(M=117.97, S D=14.62)$. This score is lower as compared to previous studies using the same scale. The Pearson correlation between mental health literacy and help-seeking behavior showed a negative, weak correlation ( $r=-$ .139) which is in contrast with the previous studies using the same scale. There is a significant difference in the mean score of the students who answer Yes and No for the screening question on knowing people with mental health disorders. In summary, the topic of mental health literacy is a new area to be explored in Malaysia and limited number of researches is available to compare the data.
\end{abstract}

Keywords: Mental Health Literacy, Help-Seeking Behavior, University Students, Young Adults

\section{Introduction}

Mental health literacy is a term introduced by Jorm et. al. (1997) which defined as "knowledge and belief about mental disorder which aid their recognition, management and prevention." The component of mental health literacy (Jorm et. al, 1997) includes (1) ability to recognize specific disorder, (2) knowledge of how to seek information, (3) knowledge of risk factors, (4) knowledge of causes of mental illness, (5) knowledge of self-treatment, (6) knowledge of 
professional help available and (7) attitudes that promote recognition or appropriate helpseeking behavior. Help seeking behavior is the intention of an individual to seek for help, especially if one is experiencing personal or emotional problems. According to Collaway (2008) help-seeking in the aspect of mental health referred to as the intention of seeking professional help such as a counsellor or psychologist to release psychological distress. Helpseeking can also occur either formal or informal way of asking for help. Informal help is the preference of asking help from the closest person such as the family members, parents, friends or others. On the other hand, formal help-seeking involves asking for help from the professional helps such as a counselor and psychologist. (TPB; Ajzen, 1991, 2002) highlighted the used of theory of Planned Behavior in attitude-intention which mentioned that helpseeking intention is closely related to actual behavior and other construct.

Gorczynski, Sims-schouten, Hill and Wilson (2017) conducted a study on mental health literacy to examine whether it predicts help seeking behavior and better mental health outcome among United Kingdom (UK) students. Results showed that mental health literacy is positively correlated with attitude for seeking help but not significantly for better mental health well-being. In Malaysian context, a study conducted by Brahim et. al (2019) investigated the influence of depression literacy, mental illness belief and stigma influence help-seeking among secondary school and university students of low socioeconomic status of Bottom 40\% (B40) with earnings of RM3, 900 a month or less in Malaysia. Correlation analysis among the variables of depression literacy, general help seeking attitude, self-stigma of seeking help, negative belief toward mental illness and age with the mental help seeking attitude, only self-stigma on help-seeking, general help seeking attitude and age showed a significant relationship with help-seeking attitude whereas depression literacy yielded a very low correlation. These two findings from two countries is contradicted where Gorczynski et al (2017) showed a positive correlation of mental health literacy to help-seeking behavior while depression literacy and help-seeking attitude showed a lower correlation in Ibrahim et. al (2019). This is something interesting to be investigated in this current study.

A study on depression literacy is conducted by Thai and Nguyen (2018) revealed that $32 \%$ of the respondents used accurate label of depression through the vignette and from the sample, $82.1 \%$ person would seek help. This study, however, is descriptive in nature which only reported the percentage without identifying the relationship between depression literacy and help-seeking behavior. Yu Yu et al. (2015) in the study to determine the predictors of help-seeking intention through multivariate analysis revealed that mental health knowledge is one of the predictors for help seeking intention.

Despite the numerous researches of mental health literacy and help-seeking behavior, some gap in the research were identified as also addressed by Furnham \& Hamid (2014) through their systematic review on study related to mental health literacy. It is found out that majority of mental health literacy study focus on depression and schizophrenia and small amounts for other mental illness. The methodology of the studies also ranging from quantitative and qualitative with different vignettes and measures which make the identification and results could not be compared between one another. This is also important in this current research to use the developed mental health literacy scale to provide a standardized and comparable finding. 
Mental health literacy is a growing subject area and some research are progressing in identifying suitable measures to evaluate the level of mental literacy and the importance to be discussed in the effort to address mental health issues. The theory revolves the derivation of mental health literacy is not clearly explained based on the previous research and more developed theories have been used to explain help-seeking behavior such as the theory of planned behavior (Ajzen \& Madden, (1986); Fishbein \& Ajzen, (1975) and the health belief model (Rosenstock, 1966). Despite numerous researches have been conducted, the method for measuring the level of mental health literacy varies from qualitative method using vignette and the interview to quantitative method using a questionnaire and survey. The research is conducted to test the following hypothesis

The aim of this study have threefold (1) to identify levels of mental health literacy among Malaysia university students, (2) to identify the relationship between mental health literacy and help seeking behaviour and (3) to identify the significant difference in mental health literacy score for students who know, do not know or maybe know someone with mental health disorders. The outcome of the research can provide more updated data regarding the level of mental health literacy among selected sample of the population. This is important as more updated data will be helpful in reflecting the awareness of the population about mental health and the tendency of seeking help.

\section{Methodology}

The study adapted a quantitative design using survey. The questionnaires were distributed to the participants through an online survey platform which provided details of the study and an informed consent. If consent was indicated, the participants may proceed on answering the survey in the online survey platform.

\section{Instruments and Materials}

The quantitative survey involved three parts of questions to identify the objective of the research. The first part consisting Participant Demographic Information related the participant background information. The second part of the questionnaire is the Mental Health Literacy Scale, which is in English language. The third section is the General Helpseeking Questionnaire, measuring the likelihood of individuals seeking help if facing mental health problem.

\section{Mental Health Literacy Scale (MHLS)}

Mental Health Literacy Scale was developed by O'Connor and Casey (2015), consisting of 35 items measuring mental health literacy through the assessment six subscales which are (1) disorder recognition, (2) risk factor knowledge, (3) self-treatment knowledge, (4) available professional treatments (5) information seeking knowledge and (7) attitude towards promoting positive mental health. The items consisted mixed type of scales which questions 1 to 15 are to be answered in 4-Likert scale, whereas questions 16 to 35 are to be answered in 5 Likert scale. MHLS also has a reversed scoring item which is item number 10, 12, 15, 20, $21,22,23,24,25,26,27$ and 28. The MHLS has the minimum score of 35 and a maximum score of 160. A higher score indicates higher mental health literacy. MHLS has shown to have good internal consistency (Cronbach $\alpha=.873$ ) and test retest reliability $r=.797),(p<0.001)$ (O'Connor and Casey, 2015). Question 9 and 10 of the risk factor knowledge is modified to be 
specific to Malaysian context, which in this case "Australia" was changed to "Malaysia". Current study of MHLS shown a good internal consistency of Cronbach's $\alpha=.839$.

\section{General Help-seeking Questionnaire (GHSQ)}

General Help-Seeking Questionnaire (Wilson et. al., 2007) was used to assess the intention of seeking help due to mental health problems. The question is "If you are having personal or emotional problem, how likely is it that you would seek help from the following people?" For this type of question, participants need to rate the likelihood they are seeking help to on a scale of 1 (extremely unlikely) to 7 (extremely likely). The options of the group of people to seek help are intimate partner, friend, mental health care professional, religious leader, parent, other relative/family member, phone/helpline, doctor/GP. There is also the option of "I will not seek help from anyone" and "I would seek from other not listed from above". The minimum score is 10 and the maximum score is 70 . Higher score indicated a higher intention to seek help for mental health problems. The data can also be yielded to identify the most group of people participants will help seek to. Table 3.3 showed the GHSQ in which all the questions are to be answered in 1-7 Likert scale.

\section{Procedure}

The study used convenience sampling to recruit the participants. The sampling was chosen as for the ease of approach and easily reachable and due to convenient accessibility. A web link was disseminated to the targeted participants, which consist of details of the study and the questionnaire. An informed consent was also provided in the beginning of the questionnaire in which participants were asked to tick the box to reflect their consent in participating in this research. If consent were indicated, the participants complete the questionnaire online and it was submitted to the researcher once they complete answering all questions. At the end of the survey, the researcher attached a soft copy of a free access mental health handbook prepared Malaysian Mental Health Association (MMHA) and Malaysian Psychiatric Association which can be downloaded through a google drive link. This handbook is specifically attached at the end of the survey as a supplement for the participants to have more knowledge about mental health.

\section{Data Analysis}

Data analysis was completed using SPSS 23. The first data analysis was a descriptive statistic for respondents' demographic information, MHLS scores and GHSQ score. The mean and standard deviation of the scores are also described. This was also to answer the first objective on the level of mental health literacy among UPSI students, which is reflected by the mean score of the MHLS. Besides that, a descriptive statistic on the screening question is also described to identify the number of participants who answer 'Yes', 'No' or 'Maybe' on the questions of (1) Do you have any knowledge about mental health and its disorder? and (2) Do you know someone (e.g family, friends etc.) that experience mental health disorder? Second data analysis involved inferential analysis using the Pearson's correlation to examine the correlation between mental health literacy and help seeking behavior. This was to answer the second objective in identifying the relationship between mental health literacy and helpseeking behavior. The third objective was explored using a one-way ANOVA to examine the significant difference of mental health literacy score for people answering 'Yes', 'No' or 'Maybe' on the second screening question. 


\section{Results}

\section{Descriptive Analysis of Demographic Information}

The total number of participants took part in the study was $\mathrm{N}=130$. Female showed higher percentage of participation (80.8\%) as compared to male (19.2\%). The mean age of participants took part in the study was $(M=22.05, S D=2.19)$ in which the minimum age was 19 years old while the maximum age was 40 years old. Figure 4.1 showed the distribution of age, which denoted 22 years old had the highest frequency $(28.5 \%)$, followed by 23 years old (23.1\%) and 21 years old (21.5\%).

\section{Mean Score of Mental Health Literacy}

Descriptive analysis revealed the mean score of the sample $(M=117.97, S D=14.62)$ with the minimum score 87 and the maximum score 152. This mean score answered the first research question on the level of mental health literacy of UPSI students. Comparison of the mental health literacy scores with other study utilizing similar instruments are discussed in detail in the discussion chapter.

\section{Descriptive Analysis for Screening Questions}

The questionnaire also involved a screening question at the beginning of the question which as the respondents the following question (1) Do you have any knowledge about mental health and its disorder; and (2) Do you know someone (eg. family, friends etc) experiencing mental health disorder. For the first screening question, $n=91$ participants (70\%) answered Yes, followed by $n=3$ answered No $(2.3 \%)$ and $n=36(27.7 \%)$ answered that they maybe have knowledge about mental health. The second screening question which will be used for the inferential analysis revealed result of $n=72$ (55.4\%) participants answered 'Yes' that they know someone having mental health disorder, $n=38$ (29.2\%) answered 'No' and $n=20$ (15.4\%) answered 'Maybe'. The data will be used further to answer the third research question.

Table 1 showed the descriptive analysis of the scores of MHLS based the screening questions. This part of information is useful for the next inferential analysis. From the table, for the mean scores of mental health literacy for participants who answer 'Yes' is $n=71$ with $M=122.12$, $S D=13.81, n=38$ participants answer 'No' $(M=110.34, S D=12.98)$ and $n=117$ participants answer 'Maybe' ( $M=117.50, S D=15.10)$.'

Table 1 Descriptive analysis of scores of MHLS of the second screening question

\begin{tabular}{cccc}
\hline $\begin{array}{c}\text { Do you know someone (eg. family, } \\
\text { friends etc) experiencing mental } \\
\text { health disorder }\end{array}$ & $\mathrm{N}$ & $\begin{array}{c}\text { Mean of MHLS } \\
\text { score }\end{array}$ & Std. Deviation \\
\hline Yes & 72 & 122.12 & 13.816 \\
No & 38 & 110.34 & 12.983 \\
Maybe & 20 & 117.50 & 15.105 \\
Total & 130 & 117.97 & 14.622 \\
\hline
\end{tabular}

\section{Descriptive Score for General Help Seeking Questionnaire}

General Help-Seeking Questionnaire consists of ten questions of 7-Likert scale which is asking the tendency to seek help according to the items given. The score of GHSQ yielded the mean score of general help seeking questionnaire of $(M=42.82, S D=8.876)$ which the minimum score is 20 while the maximum score is 64 . The second analysis involved the mean score of each item as shown in Table 2. 
Table 2 Descriptive statistic for mean score on each item of GHSQ

\begin{tabular}{|c|c|c|c|}
\hline No & Item & Mean & Std. Deviation \\
\hline 1. & $\begin{array}{l}\text { Intimate partner (e.g., girlfriend, } \\
\text { boyfriend, husband, wife) }\end{array}$ & 5.21 & 1.724 \\
\hline 2. & Friend (not related to you) & 3.62 & 1.840 \\
\hline 3. & Parent & 5.32 & 1.775 \\
\hline 4. & Other relative/family member & 4.30 & 1.759 \\
\hline 5. & $\begin{array}{l}\text { Mental health professional (e.g. } \\
\text { psychologist, social worker, } \\
\text { counsellor) }\end{array}$ & 5.57 & 1.436 \\
\hline 6. & Phone helpline (e.g. Lifeline) & 4.17 & 1.843 \\
\hline 7. & Doctor/GP & 4.98 & 1.796 \\
\hline 8. & $\begin{array}{l}\text { Minister or religious leader (e.g. } \\
\text { Priest, Rabbi, Chaplain) }\end{array}$ & 3.84 & 1.879 \\
\hline 9. & $\begin{array}{l}\text { I would not seek help from } \\
\text { anyone }\end{array}$ & 2.71 & 1.967 \\
\hline 10. & $\begin{array}{l}\text { I would seek help from another } \\
\text { not listed above. }\end{array}$ & 3.10 & 1.863 \\
\hline
\end{tabular}

From Table 2, the highest mean score to seek help is to the mental health professional $(M=5.57, S D=1.436)$ followed by parents $(M=5.32, S D=1.775)$ and intimate partner $(M=5.21$, $\mathrm{SD}=1.724)$. The option I would not seek help from anyone obtained the lowest mean score $(M=2.71, S D=1.967)$.

\section{Relationship between Mental Health Literacy and Help-seeking Behaviour}

Pearson correlation was used to identify the relationship between Mental Health Literacy Scale and General Help-Seeking. The result showed a week negative correlation ( $r=-.139$, $n=130, p>.05)$. The negative direction of the correlation indicated that the higher the mental health knowledge, the lower the possibility to seek help. This is in contrast with the proposed hypothesis and other research conducted by other researchers. From the data analysis, it showed that $\mathrm{H}_{0}$ is rejected; there is negative relationship but not significant between mental health literacy and help-seeking behaviour.

\section{Comparison between Groups of Students Who Know People with Mental Health Disorder and Mental Health Literacy Score}

One-way ANOVA with post hoc test was used to measure the significance difference between three groups of people that answered their knowledge for someone having mental health disorder. The independent variable is the three level of groups know someone having mental health disorder (Yes, No and Maybe). The continuous dependent variable is mental health literacy scores. Table 3 showed the generated result of the one-way ANOVA of MHLS. A test of homogeneity of variance was also conducted.

Table 3 One-Way ANOVA MHLS

Dependent variable: MHLS

\begin{tabular}{llllll}
\hline & Sum of Squares & df & Mean Square & F & Sig. \\
\hline Between Groups & 3458.449 & 2 & 1729.225 & 9.104 & .000 \\
Within Groups & 24123.428 & 127 & 189.948 & & \\
Total & 27581.877 & 129 & & & \\
\hline
\end{tabular}


From table 3, the significant value yielded through the one-way ANOVA is .000 which is less than .05 showed that there is a significant difference on the mean score of the dependent variable (MHLS score) for the three groups (Yes, No, Maybe). A test of homogeneity is carried out to determine whether the groups of participants have the same distribution of variance of the single categorical variable. The output of the test showed a significant value of .600 which is more than .05. Pallant (2016) stated that if the value needs to be greater than .05 for the assumption of homogeneity is not violated. This means that it does not violate the assumption of homogeneity of variance. The statistical significance of the differences between each pair of groups is described further on the post-hoc test as shown in Table 4.

Table 4 Post-hoc test on the statistical significance of the differences between each pair of groups

\begin{tabular}{|c|c|c|c|c|}
\hline $\begin{array}{l}\text { (I) Do you } \\
\text { someone (eg. } \\
\text { friends } \\
\text { experiencing } \\
\text { health disorder }\end{array}$ & $\begin{array}{l}\text { know }(\mathrm{J}) \text { Do you } \\
\text { family,someone (eg. } \\
\text { etc)friends } \\
\text { mentalexperiencing } \\
\text { health disorder }\end{array}$ & $\begin{array}{l}\text { know } \\
\text { family, } \\
\text { etc)Mean Difference (I- } \\
\text { mentalJ) }\end{array}$ & Std. Error & Sig. \\
\hline \multirow[t]{2}{*}{ Yes } & No & $11.783^{*}$ & 2.763 & .000 \\
\hline & Maybe & 4.625 & 3.484 & .383 \\
\hline \multirow[t]{2}{*}{ No } & Yes & $-11.783^{*}$ & 2.763 & .000 \\
\hline & Maybe & -7.158 & 3.807 & .149 \\
\hline \multirow[t]{2}{*}{ Maybe } & Yes & -4.625 & 3.484 & .383 \\
\hline & No & 7.158 & 3.807 & .149 \\
\hline
\end{tabular}

The post hoc test as shown in Table 4 told exactly where the differences among the group occur. From the mean difference, Yes and No group showed a significantly different from one another at the $p<.05$ as it is indicated by the asterisk $\left({ }^{*}\right)$. From the results presented above, only group 1 (Yes) and Group 2 (No) are statistically different from one another. That is, the respondents that answer Yes and the respondent that answer No differ significantly in term of their Mental Health Literacy score. This result confirmed that there is a significant difference between students who know, do not know or maybe know someone with a mental health disorder and their mental health literacy scores.

\section{Discussion}

In this study, the finding of the mean scores of mental health literacy reflected the level of mental health literacy of UPSI students. The total number of participants for this study is $\mathrm{N}=130$ which is lower than the study conducted by O'Connor and Casey (2015) among Australian students $(\mathrm{N}=372)$. The finding of this study demonstrated the MHL mean score of $M=117.97$ whereas the study by O'Connor and Casey (2017) revealed a MHL mean score of $M=127.38$. A similar study to measure mental health literacy by using similar scale was also conducted by Gorczynski (2017) with the sample of participants from 379 UK university students revealed a mean score of mental health literacy of $M=122.88$. The comparison of the mean score of the MHLS utilizing the same scale showed higher mean score of MHL as compare to the current study. 
Another similar study utilizing the MHLS is a study conducted by Recto and Champion (2017) among perinatal adolescents. The selection of participants is different and only involved 30 participants of pregnant and postpartum adolescents. However, the study has some modification on the questions in which they are eliminating two items of personality disorder and dysthymia and modify the gender-case specific scenarios which make the minimum scores to be less by two points and the maximum score is less by six points. Results revealed adolescent who experiencing perinatal depression $(M=74.45)$ has higher $\mathrm{MHL}$ as compared to adolescent who did not have perinatal depression $(M=67.35)$. Both mean scores are lower than the current study conducted by the researcher. However, the number of participants relatively low as compared to the current study. Vermaas, Green, Haley and Haddock (2017) administered the similar MHL scale to 238 clergy of different denominations across the United States. This study aims to compare the different of MHL score among different study groups consisting of evangelical Protestant $(n=118)$, mainline Protestant $(n=78)$, Catholic ( $n=39)$, historically Black Protestant $(n=3)$ participants. Overall mean of MHL score in this study is $M=134.20$ which is even higher as compared to study by O'Connor and Casey (2017); Gorczynski (2017); Recto and Champion (2017) and the current study $(\mathrm{M}=117.97)$.

From the finding and the discussion, the level of mental health literacy is measured by obtaining the mean scores of the participants. However, it has to be noted that there is a difference in the number of participants, which the highest number of participants is $(n=379)$ Gorczynski (2017) and the lowest number of participants is from the study conducted by Recto and Champion (2017), only involved $(\mathrm{N}=30)$ participants. Due to the limited number of researches utilizing this questionnaire, comparison of the mean scores obtained is to be interpreted with caution.

In term of the terminologies used in the MHLS scale, researches that examined mental health literacy (Furham et. al, 2014; Yousef et. al, 2014) found that students have difficulties in recognizing and understanding the symptoms of mental illness. Despite their outcome, the systematic review they conducted to compare the mental health literacy mostly utilized the combination of questionnaire, either by using vignette, questionnaire or both. It is also interesting on the finding by Furham et. al (2014) which analyzed the use of mental health literacy among non-western countries as it allowed the cross countries comparison. This may be one of the explanations on the understanding of the terminologies of the mental health used in the questionnaire which is also reflected by the choice of answering the question.

However, it is also highlighted in their finding that most of the recognition of mental health disorder is depression and schizophrenia, with a low number of researches include other disorders. Furham et. al (2014) also make a deduction that the more developed the countries, the higher the mental health literacy, based on his finding. The different vignette used across the countries are also something that need to be considered as a standardize test is not available, hence making the comparison less reliable. To highlight on the finding especially in research on mental health literacy conducted in Malaysia, Furham et al (2014) identified three researches conducted in Malaysia (cross culturally among participants of different races; Chinese (Loo \& Furnham, 2012), Malay (Swami et. al., 2010) and Indian (Loo \& Furnham, 2013) which they compared the significance different between the location of living, either urban or rural. From the findings, urban participants obtain a higher percentage 
of answering correctly for the vignette study of depression and schizophrenia compared with rural participants. This is true for all the different races.

The score from GHSQ showed that the mean score is $(M=42.82, S D=.212)$ where the minimum score is 20 while the maximum score is 64 . Compared with a study conducted by Gorzynski (2017), the mean score of his study involved 379 participants is ( $M=33.55, S D=7.89$ ) which is lower than the current study. For individual items, finding of the study revealed that mental health professional obtained the highest mean score $(M=5.57)$ which reflected the most group of people participants seek help to, followed by parent $(M=5.32)$ and intimate partner ( $\mathrm{M}=5.21)$. The option I would not seek help from anyone obtained the lowest mean score ( $M=2.71)$. Different with the study conducted by Gorzynski (2017), participants are most likely seeking help from intimate partner, followed by parent whereas the least frequency participants seek help from health professionals. These findings shed some light on the pattern of seeking help, especially among university students if they are having emotional distress of problems. Wilson (2005) conducted a validation study using GHSQ specific on different problem type which is suicidal thoughts and emotional problems on high school students. This is different as compared to the current study, which referring generally to the mental health problem. Results showed that for suicide-related problems, students mostly seek help from friends compared to family and for non-suicidal problem, students tend to seek help from friends rather than no one. This result, specifically looking at the aspect of the person participants were seeking help to, either in formal or informal sources.

The results of the study revealed a weak negative correlation between mental health literacy and help seeking behavior. This is in contrast with previous study conducted by O'Connor and Casey (2015) and Gorzynski (2017) which showed a positive correlation between mental health literacy and help-seeking behavior. The previous study was conducted in the Australia and United Kingdom compared to this study which is the first time conducted in Malaysia. The difference of the relationship can be explored more on the background of mental health concept of each countries also the exposure of the mental health information obtained by the participants. Despite unclear justification of the contrast of the finding, the researcher needs to obtain more information and comparison with other findings conducted in Malaysian setting utilising the same scale.

The current finding is also in contrast with the study conducted by Bonabi et. al. (2016) which measure the relationship between mental health literacy, attitude to help seeking and perceived needs. The study utilized different scales to measure mental health literacy, which is 22-item Depression Literacy Questionnaire and 10-item Attitudes Toward Seeking Professional Psychological Help Scale-Short Form (Fischer and Farina, 1995). The study showed that mental health literacy, positive attitude to help seeking and perceived need for treatment is significant for predict the use of psychotherapy over time. Study by Coles et. al (2016) on addressing the knowledge and belief of mental health illness among adolescent $(\mathrm{N}=1104)$ revealed that adolescent had identified depression better than social anxiety disorder and most likely recommend seeking help for it. Despite this, only less than $50 \%$ of the participants can identify depression correctly using the vignette test. Family, friends, and counsellors were group of people adolescent mostly seek help to. This study also not supporting the finding from the current study however provided a comparable data in identifying the type of people adolescent mostly seeking help to. 
In a study conducted by Waldman et. al (2019) on the mental health literacy and helpseeking behaviour among unemployed people with mental health problems $(N=301)$ revealed a positive correlation between the variables. The researchers used three measures in this study to assess the mental health literacy which are Mental Health Knowledge Schedule (MAKS), the Depression Literacy Scale (DLS), and the Depression with Suicidal Thoughts Vignette. In their structural equation modelling (SEM), it was identified that higher MHL was significantly associated with increased intentions and behaviour to seek help formally through professionals and informally through family and friends.

Results for this research question revealed a significant difference between mental health scores of students who answer Yes and No for the question on "Do you know someone (eg. Family, friends, etc.) experiencing mental health disorder?" The total number of students who answer Yes is ( $n=72, M=122.13)$, No is $(n=38, M=110.34)$ and Maybe $(n=20, M=117.50)$. Using one way ANOVA with post hoc test, there is a significant difference between the three groups but the group that answer Yes and No showed a significantly different from one another.

During the development of MHLS instrument, O'Connor et al (2015) also conducted a series of independent t-test on a known group sample for assessing the reliability and validity. The results revealed that individuals who had family members or friends with mental health illness had significantly higher $\mathrm{MHL}(M=129.53, \mathrm{SD}=12.12)$ as compared to groups of individuals who did not know anyone having mental health illness ( $M=122.69$, SD12.49), $t$ $(370)=5.00, p<.001$. It also measured the magnitude of difference (mean difference $=6.84$, $95 \%, C l=4.15-9.52)$ was medium ( $d=.56)$. This finding supports the hypothesis of the second research questions that there is significant difference in the mental health scores among students who has encountered with individuals having mental health illness. Riebschleger (2019) conducted a pre post-test on the mental health literacy of youth with family members with mental illness utilizing the Knowledge of Mental IIIness and Recovery (K-MIR) scale. This test specifically targeted on youth that have family with mental illnesses such as depression, anxiety or substance abuse. The mental health literacy is measured before the intervention program and compared after the intervention program. Results revealed a significant increase in mental health literacy during the post experiment and reported of $90 \%$ improve of positive coping strategy.

On the other hand, study by Mendenhall and Rauenholtz (2013) target on different sample which was the mental health literacy among parents having children with mental health illnesses. This study utilizing the secondary data analysis which the first survey was to be answered by the children to identify that they were experiencing any mood disorder or mental health problem and the second survey was answered by the caregivers which were analyzed for obtaining the secondary data analysis for baseline assessment prior to randomization and treatment. The Understanding of Mood Disorders Questionnaires (UMDQ) and Treatment Belief Questionnaire (TBQ) are used in this study. The study revealed that mental health literacy was higher among parents who are female, white, highly educated and had children diagnosed with bipolar or received multiple services. It was also found out in this study that the lifetime experiences with mental health disorders also predicted mental health literacy. 


\section{Limitation and Recommendation for Future Research}

Several limitations are identified in this study. Firstly, the study is conducted only in one university in Malaysia, thus limiting generalization of this finding. Future studies can consider conducting the study in several universities to get a more meaningful finding. Secondly, the instrument is in English language in which English is not the first language for most of the Malaysians. The terminologies of mental health might not be literally understood by the respondents, hence may influence on the choice of answer. Future studies can consider translate the instruments to Malay language and conduct psychometric test before disseminating to the participants. Lastly, only one dependent variable was used in this study which is the mental health literacy. Future research can include more variables as part of the study to explore other factors that may affect the findings.

\section{Conclusion}

In summary, although the findings showed a contrast result as compared to the previous studies, this study provides a valuable data on the level of mental health literacy among Malaysian students. The descriptive data of the help-seeking behavior is also useful in identifying the most groups of people participants tend to seek help when encountering emotional and mental health problems. The concept of mental health literacy is still new in Malaysia and in the light of this study, it is hopeful that the concept of mental health literacy is as important of physical health literacy so that the individual is also aware about their mental health well-being.

\section{Acknowledgement}

The research was conducted in the Universiti Pendidikan Sultan Idris.

\section{Corresponding Author}

\section{Asma Perveen}

Senior Lecturer, Department of Psychology and Counseling, Sultan Idris Education University, Malaysia.

Email: asmaperveen@fpm.upsi.edu.my

\section{References}

Ajzen, I., \& Madden, T. J. (1986). Prediction of goal-directed behavior: Attitudes, intentions, and perceived behavioral control. Journal of experimental social psychology, 22(5), 453474.

Benyon, K. (2014). Health literacy. InnovAiT, 7(7), 437-440.

Berry, C., Michelson, D., Othman, E., Tan, J. C., Gee, B., Hodgekins, J., ... \& Fowler, D. (2019). Views of young people in Malaysia on mental health, help-seeking and unusual psychological experiences. Early intervention in psychiatry.

Bonabi, H., Müller, M., Ajdacic-Gross, V., Eisele, J., Rodgers, S., Seifritz, E., ... \& Rüsch, N. (2016). Mental health literacy, attitudes to help seeking, and perceived need as predictors of mental health service use: a longitudinal study. The Journal of nervous and mental disease, 204(4), 321-324.

Calloway, S. J., Kelly, P., \& Ward-Smith, P. (2012). Stressors and barriers to help seeking for psychological distress among students attending a rural university. Journal of Rural Mental Health, 36(1), 3. 
Calloway, S. J. (2008). Barriers to help-seeking for psychological distress among students attending a small rural university. University of Missouri-Kansas City.

Coles, M. E., Ravid, A., Gibb, B., George-Denn, D., Bronstein, L. R., \& McLeod, S. (2016). Adolescent mental health literacy: Young people's knowledge of depression and social anxiety disorder. Journal of Adolescent Health, 58(1), 57-62.

Corrigan, P. W., \& Wassel, A. (2008). Understanding and influencing the stigma of mental illness. Journal of psychosocial nursing and mental health services, 46(1), 42-48.

DeVellis, R. F. (2003). Scale development: Theory and applications. Thousand Oaks, CA: SAGE Publications.

Fishbein, M., \& Azjen, I. (1975). Belief, Attitude, Intention and Behaviour: An Introduction to Theory and Research. Reading, MA: Addison-Wesley.

Furnham, A., \& Hamid, A. (2014). Mental health literacy in non-western countries: a review of the recent literature. Mental Health Review Journal, 19(2), 84-98.

Gorczynski, P., Sims-Schouten, W., Hill, D., \& Wilson, J. C. (2017). Examining mental health literacy, help seeking behaviours, and mental health outcomes in UK university students. The Journal of Mental Health Training, Education and Practice, 12(2), 111120.

Gravetter, F. J., \& Wallnau, L. B. (2013). Statistics for the Behavioral Sciences. Belmont, CA: Wadsworth Publishing.

Gulliver, A., Griffiths, K. M., \& Christensen, H. (2010). Perceived barriers and facilitators to mental health help-seeking in young people: a systematic review. BMC psychiatry, 10(1), 113.

Hochbaum, G., Rosenstock, I., \& Kegels, S. (1952). Health belief model. United States Public Health Service, W432W8784.

Ibrahim, N., Amit, N., Shahar, S., Wee, L. H., Ismail, R., Khairuddin, R., ... \& Safien, A. M. (2019). Do depression literacy, mental illness beliefs and stigma influence mental health helpseeking attitude? A cross-sectional study of secondary school and university students from B40 households in Malaysia. BMC public health, 19(4), 544.

Jorm, A. F., Korten, A. E., Jacomb, P. A., Christensen, H., Rodgers, B., \& Pollitt, P. (1997). "Mental health literacy": a survey of the public's ability to recognise mental disorders and their beliefs about the effectiveness of treatment. Medical journal of Australia, 166(4), 182-186.

Jorm, A. F. (2012). Mental health literacy: Empowering the community to take action for better mental health. American Psychologist, 67(3), 231.

Jorm, A. F. (2015). Why we need the concept of "mental health literacy". Health communication, 30(12), 1166-1168.

Jorm, A. F., Korten, A. E., Jacomb, P. A., Christensen, H., Rodgers, B., \& Pollitt, P. (1997). "Mental health literacy": a survey of the public's ability to recognise mental disorders and their beliefs about the effectiveness of treatment. Medical journal of Australia, 166(4), 182-186.

Jung, H., von Sternberg, K., \& Davis, K. (2017). The impact of mental health literacy, stigma, and social support on attitudes toward mental health help-seeking. International Journal of Mental Health Promotion, 19(5), 252-267.

Kenney, C. A. (2019). An Examination of the Psychometric Properties of the Mental Health Literacy Scale with K-12 Educators.

Kutcher, S., Wei, Y., Costa, S., Gusmão, R., Skokauskas, N., \& Sourander, A. (2016). Enhancing mental health literacy in young people. 
Kutcher, S., Wei, Y., Gilberds, H., Ubuguyu, O., Njau, T., Brown, A., \& Perkins, K. (2016). A school mental health literacy curriculum resource training approach: effects on Tanzanian teachers' mental health knowledge, stigma and help-seeking efficacy. International journal of mental health systems, 10(1), 50.

Kutcher, S., Bagnell, A., \& Wei, Y. (2015). Mental health literacy in secondary schools: a Canadian approach. Child and adolescent psychiatric clinics of North America, 24(2), 233-244.

Malaysia National Health \& Morbidity Survey: Adolescent Mental Health 2017. (NHMS, 2017)

Mendenhall, A. N., \& Frauenholtz, S. (2015). Predictors of mental health literacy among parents of youth diagnosed with mood disorders. Child \& Family Social Work, 20(3), 300-309.

Mo, P. K., \& Mak, W. W. (2009). Help-seeking for mental health problems among Chinese. Social psychiatry and psychiatric epidemiology, 44(8), 675-684.

Nutbeam, D. (2000). Health literacy as a public health goal: a challenge for contemporary health education and communication strategies into the 21st century. Health promotion international, 15(3), 259-267.

O'Connor, M., Casey, L., \& Clough, B. (2014). Measuring mental health literacy-a review of scale-based measures. Journal of mental health, 23(4), 197-204.

O'Connor, M., \& Casey, L. (2015). The Mental Health Literacy Scale (MHLS): A new scale-based measure of mental health literacy. Psychiatry research, 229(1-2), 511-516.

Pallant, J. (2020). SPSS survival manual: A step by step guide to data analysis using IBM SPSS. Routledge.

Phang CK, Marhani M, AA Salina AA: Help-seeking pathways for in-patients with first-episode psychosis in Hospital Kuala Lumpur. Malaysian Journal of Medicine and Health Sciences (Kuala Lumpur), 2011; 7: 37-44.

Riebschleger, J., Costello, S., Cavanaugh, D. L., \& Grové, C. (2019). Mental health literacy of youth that have a family member with a mental illness: Outcomes from a new program and scale. Frontiers in psychiatry, 10, 2.

Rosenstock, I. M. (1966). Why people use health services? Milbank Memorial Fund Quarterly, 44, $94-124$.

Rosenstock, I. M. (1974). Historical origins of the health belief model. Health Education Monographs, 2, $1-8$.

Royal College of Psychiatrists (2011), "Mental health of students in higher education", available at: www. rcpsych.ac.uk/files/pdfversion/cr166.pdf (accessed 12 September 2016).

Storrie, K., Ahern, K. and Tuckett, A. (2010), "A systematic review: students with mental health problems - a growing problem", International Journal of Nursing Practice, Vol. 16 No. 1, pp. 1-6.

Thai, Q. C. N., \& Nguyen, T. H. (2018). Mental health literacy: knowledge of depression among undergraduate students in Hanoi, Vietnam. International journal of mental health systems, 12(1), 19.

Thompson, A., Issakidis, C., \& Hunt, C. (2008). Delay to seek treatment for anxiety and mood disorders in an Australian clinical sample. Behaviour Change, 25(2), 71-84.

Vermaas, J. D., Green, J., Haley, M., \& Haddock, L. (2017). Predicting the mental health literacy of clergy: An informational resource for counselors. Journal of Mental Health Counseling, 39(3), 225241. 
Waldmann, T., Staiger, T., Oexle, N., \& Rüsch, N. (2019). Mental health literacy and helpseeking among unemployed people with mental health problems. Journal of Mental Health, 1-7.

Wei, Y., McGrath, P. J., Hayden, J., \& Kutcher, S. (2016). Measurement properties of tools measuring mental health knowledge: a systematic review. BMC psychiatry, 16(1), 297.

Wilson, C.J., Deane,F. P.,Ciarrochi, J., Rickwood, D. (2007). Measuring help-seeking intentions: properties of the general help seeking questionnaire. Can. J. Couns. 39, 15-28.

Yaghmaie, F. (2003). Content validity and its estimation. Journal of Medical Education, 3(1).

Yu, Y., Liu, Z. W., Hu, M., Liu, H. M., Yang, J. P., Zhou, L., \& Xiao, S. Y. (2015). Mental health help-seeking intentions and preferences of rural Chinese adults. PloS one, 10(11), e0141889.

Zorrilla, M. M., Modeste, N., Gleason, P. C., Sealy, D. A., Banta, J. E., \& Trieu, S. L. (2019). Depression and Help-Seeking Intention Among Young Adults: The Theory of Planned Behavior. American Journal of Health Education, 1-9. 